\title{
Botulismo bovino: comprovação laboratorial do diagnóstico clínico, período 1986-1989
}

\author{
Bovine botulism: laboratorial confirmation of clinical diagnosis during the period \\ 1986-1989
}

\author{
Lucia Baldassi ${ }^{*}$, Marcio Hipolito*, Manuel Alberto S. C. Portugal*, Ercilia Maria Borgheresi Calil*, Aurélia \\ Archanja Procaci Moulin*, Débora de Cássia Pires*.
}

\begin{abstract}
BALDASSI, L. et al. Botulismo bovino: comprovação laboratorial do diagnóstico clínico, período 19861989, Rev. Saúde públ., S. Paulo, 25: 371-4, 1991. Num período de 4 anos (1986-1989) foram processados 517 materiais correspodentes a 235 casos com diagnóstico clínico de botulismo de bovinos, dos Estados de São Paulo, Mato Grosso, Mato Grosso do Sul, Minas Gerais, Goiás, Bahia, Pará, Maranhão, Distrito Federal e Roraima (Brasil). Exames laboratoriais foram realizados com o intuito de confirmar a suspeita clínica, detectando a toxina nos materiais correspondentes aos casos supracitados. Os tipos de toxina verificados foram " $C$ " e " $D$ " presentes no fígado e conteúdos de estômago e intestinos, que perfaziam o maior número das amostras remetidas. $O$ pequeno número de casos confirmados leva à suposição de que outras enfermidades devem estar envolvidas nessas mortes, ainda que se considere possíveis resultados falso negativos.
\end{abstract}

Descritos: Botulismo, veterinária. Doenças dos bovinos, diagnóstico. Toxinas botulínicas, análise.

\section{Introdução}

O Botulismo nos bovinos, descrito no Brasil pela primeira vez em 1970, no Piauí ${ }^{4}$ e, posteriormente, 1983, em Alegrete, Rio Grande do Sul' ${ }^{12}$, constitui uma intoxicação alimentar provocada pela ingestão de toxina pré-formada pelo Clostridium botulinum no alimento. $\mathrm{Na}$ espécie bovina, os animais podem intoxicar-se pela ingestão de restos de carcaças, portadoras da toxina, encontradas no pasto ${ }^{12.24}$; por silagens, onde a bactéria presente no organismo de aves e pequenos mamíferos que são compactados, por descuido, durante o enchimento do silo, encontra aí condições de se multiplicar e produzir a toxina ${ }^{7.19}$; ou por ingestão de água onde cadáveres de animais, contendo a toxina, possam ter sido lança$\operatorname{dos}^{6}$. Mais recetemente, carcaças em camas de frango adicionadas às rações têm conduzido à ocorrência do botulismo $0^{9.16}$, porém, com frequiência pouco significativa por se tratar de um hábito ainda não muito difundido.

No Brasil, onde grandes áreas do solo são pobres em minerais, notadamente o fósforo ${ }^{4}$, os acidentes botulínicos ocorrem mais comumente pela ingestão de restos de carcaças contaminadas. Em virtude da carência mineral, os animais são levados a desenvolver hábitos de aberração do apetite, ingerindo restos de cadáveres.

* Seção de Bacteriologia Animal do Instituto Biológico de São Paulo - São Paulo, SP - Brasil.

Separatas/Reprints: L. Baldassi - Caixa Postal 7119 01051 - São Paulo, SP - Brasil.

Publicação financiada pela FAPESP - Processo Medicina 90/4602-1
O diagnóstico desta intoxicação fundamenta-se na deteç̧ão da toxina botulínica nos conteúdos gástrico e intestinal, hemosoro e fígado do animal morto ou doente e, quando possível, no próprio alimento suspeito de estar contaminado ${ }^{3}$. A presença de $\mathrm{Cl}$. botulinum nos órgãos dos animais afetados não constitui base definitiva no estabelecimento do diagnóstico, uma vez que a bactéria não encontra condições necessárias para se multiplicar e produzir a toxina "in vivo""!.

A confirmação laboratorial do diagnóstico clínico, que se constitui no objetivo principal do presente trabalho, é de extrema importância uma vez que a sintomatologia nervosa apresentada nesses casos é comum a muitas enfermidades. $O$ tratamento de botulismo, em nível de rebanho, não é economicamente viável porém, medidas profiláticas gerais de manejo e específicas de vacinação devem ser adotadas.

\section{Material e Método}

Duarante 4 anos (1986-1989) foram efetuados exames laboratoriais em materiais diversos oriundos de bovinos mortos ou sacrificados com suspeita clínica de botulismo. Esses eram originários dos Estados de São Paulo, Mato Grosso, Mato Grosso do Sul, Minas Gerais, Goiás, Bahia, Pará, Maranhão, Distrito Federal e Roraima.

Foram registradas 235 ocorrências, sendo examinados: amostras de fígado, conteúdos de rúmen, omaso, abomaso, retículo e intestinos, além de hemosoro. Destes, no mínimo, duas amostras de cada caso clínico foram examinadas, perfazendo um total de 517 testes realizados (Tabela 1). 
Tabela 1. Resultados dos testes para toxina termolábil ou botulínica realizados em amostras de bovinos, tomandose por base os anos e material considerado, Brasil, 198689.

\begin{tabular}{lccccc}
\hline Ano & 1986 & 1987 & 1988 & 1989 \\
Toxina & g t b & g l b & g l b & g t b \\
+ t- & +++- & +++ & +++- & +++- \\
\hline
\end{tabular}

\begin{tabular}{|c|c|c|c|c|c|}
\hline úmen & 401 & 1039 & 34110133 & $\begin{array}{llll}34 & 5 & 5 & 29\end{array}$ & 31550 \\
\hline maso & - & -- & $\begin{array}{lllll}1 & 0 & 0 & 0 & 1\end{array}$ & - - & 2110 \\
\hline bomaso & - & & 200002 & - & 20000 \\
\hline ettículo & - & -- & $\begin{array}{lllll}1 & 0 & 0 & 0 & 1\end{array}$ & $-\ldots$ & 100 \\
\hline intestino & 262 & 0224 & 4174334 & 2611025 & 2855 \\
\hline ado & 42 & 1140 & 4722045 & 35222033 & 3410 \\
\hline & 270 & $\begin{array}{llll}0 & 0 & 27\end{array}$ & 220000022 & 1011109 & 3111 \\
\hline
\end{tabular}

$\mathrm{b}=$ botulínica

t= termolábil

$\mathrm{g}=$ botulínicattermolábil

Com exceção do hemosoro, os demais materiais eram triturados e diluídos em tampão de gelatina fosfatada, pH 6,2, na proporção de 1:2 (peso/volume). Após um período de 12 a $18 \mathrm{~h}$ mantidas a $4^{\circ} \mathrm{C}$, as amostras homogeneizadas eram centrifugadas a $2.000 \mathrm{rpm}$ por $30 \mathrm{~min}$ em centrífuga refrigerada ${ }^{5}$.

O sobrenadante, assim obtido, era destinado à inoculação de camundongos albinos pesando entre 18 e $20 \mathrm{~g}$, na dose de $0,5 \mathrm{ml}$ por via intra-peritoneal, segundo o seguinte esquema: 7 grupos com 3 animais recebendo cada um deles um tipo diferente de inóculo.

$\begin{array}{cc}\text { Grupo animal } & \text { Inóculos } \\ \text { Grupo 1 } & \begin{array}{c}\text { - sobrenadante puro } \\ \text { Grupo 2 }\end{array} \\ \begin{array}{c}\text { - sobrenadante aquecido }\left(100^{\circ} \mathrm{C} /\right. \\ 10 \text { min.) }\end{array} \\ \text { Grupo 3 } & \begin{array}{c}\text { - sobrenadante tratado com tripsina } \\ (0,2 \%)\end{array} \\ \text { Grupo 4 } & \begin{array}{c}\text { - sobrenadante tratado com tripsina } \\ \text { e aquecido }\end{array} \\ \text { Grupo 5 } & \begin{array}{c}\text { - sobrenadante puro tratado com } \\ \text { soro anti-botulínico polivalente }\end{array} \\ \text { Grupo 6 } & \begin{array}{c}\text { - sobrenadante puro tratado com so- } \\ \text { ro anti-botulínico monovalente C }\end{array} \\ \text { Grupo 7 } & \begin{array}{c}\text { - sobrenadante puro tratado com so- } \\ \text { ro anti-botulínico monovalente D. }\end{array}\end{array}$

O hemosoro era inoculado nas mesmas condições descritas para os sobrenadantes, constituindo apenas os grupos 1,2,5,6 e 7 .

Os animais eram observados por um período de até $96 \mathrm{~h}$. Quando os representantes dos grupos $1 \mathrm{e} /$ ou 3 manifestavam sintomatologia ou morte, os dos grupos 5,6 e 7 eram submetidos à inoculação para se confirmar a presença da toxina botulínica e efetuar sua tipificação.

Para análise estatística dos dados obtidos foi realizado o teste do $\mathrm{x}^{2}$, com nível de significância de $5 \%$.

\section{Resultados}

Dos exames realizados, somente em 37 materiais (27 casos clínicos), foi verificada a presença de toxina termolábil e, em apenas 7 deles, se caracterizou a toxina botulínica dos tipos "C" $e$ " $D$ ".

Quando esta toxina estava presente no inóculo, os animais dos grupos 1 e 3 eram os que mostravam alguma sintomatologia e/ou morte. Nestes, inicialmente, observou-se tendência a isolar-se, eriçamento dos pêlos, corrimento ocular, cerramento das pálpebras, fezes aderentes ao orifício anal, esforço abdominal à respiração, perda do tono muscular bem evidente ao nível do abdome e, em seguida, morte.

$\mathrm{Na}$ presença da toxina botulínica, o grupo 5 sobrevivia em virtude da neutralização da mesma, efetuada pelo contacto prévio com o anti-soro polivalente e a sobrevivência dos animais dos grupos 6 ou 7 indicava o tipo de toxina botulínica presente no inóculo, uma vez que esta havia sido inativada pelo anti-soro específico.

Tabela 2. Resultados do teste de toxina termolábil ou botulínica em materiais oriundos de bovinos, considerando-se o ano de amostragem, Brasil, 1986-89.

\begin{tabular}{lrrr}
\hline Ano & \multicolumn{2}{c}{ Teste } & Total \\
\hline 1986 & + & - & 135 \\
1987 & 10 & 138 & 148 \\
1988 & 9 & 96 & 105 \\
1989 & 13 & 116 & 129 \\
\hline Total & 37 & 480 & 517 \\
\hline
\end{tabular}

$O$ teste do $x^{2}$ para épocas (Tabela 2) revelou nível de significância de 4,3 demonstrando que não houve influência do ano nos resultados dos testes para a toxina, podendo-se considerar o universo das amostras para a fase seguinte (Tabela 3 ) da análise, que apresentou um nível de significância de 11,1. Os 4 diferentes tipos de amostras também permitem que se faça sua decomposição entre os contrastes: conteúdo gástrico-intestino e fígado-soro; conteúdo gástrico e intestino; fígado e soro, para os quais se obteve os seguintes índices de $x^{2}: 9,6 ; 0,7$ e 0,8 . 
Tabela 3. Resultados do teste de toxina termolábil ou botulínica em materiais oriundos de bovinos, considerando-se o tipo da amostra, Brasil, 1986-89.

\begin{tabular}{lccc}
\hline Amostra & \multicolumn{2}{c}{ Teste } & Total \\
& + & - & \\
\hline Conteúdo gástrico & 13 & 135 & 148 \\
Intestino & 15 & 106 & 121 \\
Fígado & 7 & 151 & 158 \\
Soro & 2 & 88 & 90 \\
\hline Total & 37 & 480 & 517 \\
\hline
\end{tabular}

\section{Discussão e Conclusões}

Face aos números obtidos para a toxina termolábil e botulínica considerou-se, na análise, apenas presença de toxina. Assim, considerando-se a Tabela 1, verifica-se que para os anos de 1986 e 1987 ocorreram as duas, em proporções semelhantes, enquanto que para 1988 e 1989 , praticamente só ocorreu a toxina termolábil. Considerando-se apenas "toxina", não houve influência do ano na sua incidência.

Com relação a origem do material, os conteúdos gástricos $e$ intestinais, apresentaram a maior frequiência e, em termos estatísticos, equivalem-se, devendo ser os de eleição para a obtenção de amostras.

Até o momento, são conhecidos 7 tipos de toxinas botulínicas: A, B, C, D, E, F e G ${ }^{22}$. Nos bovinos são descritas as toxinas botulínicas $\mathrm{C}_{2}$ e $\mathrm{D}^{21}$.

De acordo com o "Center for Disease Control", a prova "in vivo" para a pesquisa da toxina botulínica é a de escolha, por ser bastante sensível, de alta confiabilidade e apresentar grande especificidade. Assim, o diagnóstico clínico deve ser confirmado em nível laboratorial pela detecção da toxina e sua identificação pela soroneutralização "in vivo", uma vez que o botulismo, pela sintomatologia, pode ser confundido com outras enfermidades.

O teste de ELISA tem, atualmente, sido empregado com o intuito de evitar a utilização de animais de laboratório, diminuir o tempo de diagnóstico e detectar frações não tóxicas da toxina ${ }^{17}$. A soroneutralização "in vivo" continua sendo de ampla utilização por dispensar equipamentos sofisticados e, por mais subjetiva que seja a sua interpretação, o observador treinado não deixará de perceber a sintomatologia clara e que culmina, invariavelmente, com a morte dos animais. Possui como principal fator restritivo, o uso de animais de experimentação, adicionando-se o fato de necessitar de período longo de observação para o diagnóstico difinitivo.
A simples presença do agente bacteriano não se configura como diagnóstico conclusivo, visto que, sendo $\mathrm{Cl}$. botulinum uma bactéria telúrica, esta é facilmente encontrada na natureza. Por suas característcas de agente anaeróbico, além dessa condição, necessita de $\mathrm{pH}$, temperatura e nutrientes adequados ao seu desenvolvimento e à produção da toxina, condições essas não encontradas no organismo vivo adulto".

Admitindo-se a dificiência de fósforo nas pastagens $s^{4.23}$, os animais são levados ao hábito da osteofagia, valendo-se das carcaças abandonadas nos pastos. Mesmo que um animal não tenha morrido por botulismo, seu cadáver pode ser fonte de intoxicação botulínica para outros animais ${ }^{14}$. $\mathrm{Cl}$. botulinum presente no intestino e fígado encontra no processo de putrefação e na câmara de anaerobiose, formada pela presença do couro deste animal, condições de se multiplicar e, portanto, produzir a toxina botulínica ${ }^{21}$

Nos trabalhos sobre a prevalência de esporos de Cl. botulinum no país ${ }^{8.13 .15 .25}$, admite-se que estes sejam ubiquiitários podendo, portanto, manter-se no solo por longo período de tempo, e eventualmente serem carreados a longas distâncias por diferentes espécies animais, fatores ambientais e outros mecanismos biológicos mais complexos ${ }^{10}$. Souza ${ }^{21}$ demonstra muito bem a frequiência de distribuição de esporos nos cadáveres em decomposição na região de Goiás.

Assim, devido a carência mineral das pastagens e a possível presença dos esporos do $\mathrm{Cl}$. botulinum no solo e, conseqüentemente, nos conteúdos gastrointestinais e fígado de animais sadios, o botulismo é passível de ocorrer no país.

A baixa proporção de diagnósticos confirmados não exclui a possibilidade de estarmos frente a resultados falso negativos, devendo-se considerar como causas: pequenos volumes de materiais; estocagem a temperaturas abaixo do ponto de congelamento; coletas efetuadas quando a toxina não é mais detectável'; transporte inadequado dos materiais para o laboratório ${ }^{20}$ e toxicidade não específica dos extratos nos testes de soroneutralização em camundongos ${ }^{18}$. Porém, acredita-se que outras enfermidades possam estar envolvidas ${ }^{2} \mathrm{e}$, portanto, outros diagnósticos devam ser efeutados.

Mesmo no botulismo humano onde todas as variáveis podem ser melhor controladas, levantamento feito pelo "Center for Disease Control", na investigação de 438 surtos suspeitos no período de 1964-73, confirmou-se apenas $17 \%$ destes como botulismo; para os demais, outras causas foram atribuídas ${ }^{3}$.

Assim, guardadas as devidas proporções, acredita-se que outras enfermidades possam estar envolvidas nessas mortalidades ${ }^{2}$, visto que outras toxinas bacterianas devam estar presentes. 
$\mathrm{Na}$ complexidade do quadro que ora se observa, a carência mineral é um fato notório e predominante, podendo mesmo ser encarada como fator predisponente a quadros patológicos mais complexos.

\section{Agradecimentos}

Dr. Domingos Azevedo de Oliveira, pela análise estatística, e ao Dr. José Roberto Mineo pela confirmação dos exames laboratoriais.

BALDASSI, L. et al. [Bovine botulism: laboratorial confirmation of clinical diagnosis during the period 19861989]. Rev. Saúde públ., S. Paulo, 25: 371-4, 1991. Five hundred and seventeen specimens relating to a total of 235 clinical cases of bovine botulism occurring over period of four years (1986-1989) were studied. These samples came from the States of S. Paulo, Mato Grosso, Mato Grosso do Sul, Minas Gerais, Goiás, Bahia, Pará, Maranhão, Distrito Federal and Roraima. Laboratorial tests were performed on these samples with a view to toxin detection. Toxin types $\mathrm{C}$ and $\mathrm{D}$ were detected being found in the liver and in gastric and intestinal contents. The small number of confirmed cases led to the supposition of the participation of other diseases in these deaths reported, even if false negative cases are taken into account.

Keywords: Botulism, veterinary. Catle diseases, diagnosis. Botulism toxins, analysis.

\section{Referências Bibliográficas}

1. APPLEYARD, W. T. \& MOLLISON, A. Suspected bovine botulism associated with broiler litter waste.Vet. Rec. 116: $522,1985$.

2. BALDASSI, L. Isolamento de bactérias do gênero Clostridium e deteç̧ão de toxina botulínica a partir de materiais obtidos de bovinos com suspeita clínica de botulism. São Paulo, 1986. [Dissertação de Mestrado Faculdade de Saúde Pública da USP]

3. BOTULISM in the United States, 1899-1977: handbook for epidemiologists, clinicians and laboratory workers. Washington, D.C., Department of Health, Education and Wellfare, Center for Disease Control, 1979.

4. CAMARGO, W. V. A.; FERNANDES, N. S.; SANTIAGO, A. M. H. Estudos de elementos minerais de interesse pecuário em regiões da Amazônia legal. Arq. Inst. Biol., São Paulo, 47 (4): 83-111, 1980.

5. DELAZARI, I;; CAMARGO, R.; LEITÃO, M. F. F.; SANTOS, C. A.; ANDERSON, A. W. Clostridium botulinum em pescado no litoral do Estado de São Paulo. 1 - Ocorrência em pescada-foguete (Macrodon ancylodon), bagredo-mar (Netuna barba) e sardinha verdadeira (Sardinella brasiliensis). Col. Inst. Tecnol. Alim., Campinas, 12: 1637, 1981/1982.

6. DOUTRE, M. P. Première observation de botulism animal d'origine hydrique. Rev. Elev. Med. Vet. Pays trop.. Paris, 22: 29-31, 1969.
7. ENFORS, E.; GUNNARSON, A.; HURVELL, B.; RINGARP, N. Outbreak of botulism caused by Clostridium botulinum type $\mathrm{C}$ in cattle. Sven. Veterinaertdn., 27: 333-9, 1975.

8. FERREIRA, M. S.; NISHIOKA, S.; A.; ALMEIDA, A. B.; SILVEIRA, P. U. P.: SOUZA, M. C.; STORTI, P. C.; ZENEBON, O.; GELLI, D. S.; SOUZA, A. Botulismo: considerações acerca de oito casos ocorridos no Triângulo Mineiro, Minas Gerais, Brasil. Rev. Inst. Med. Trop. S. Paulo, 29: 137-41, 1987.

9. GLEGG, F. G.; JONES, T. O.; SMART, J. L.; McMORTY, M. J. Bovine botulism associated with broiler litter waste. Vet. Rec., 117: 22, 1985.

10. HARIHARAN, H. \& MITCHELL, W. R. Type C botulism: the agent, host spectrum and environment. Vet. Bull, 47(2): 95-103, 1977.

11. HUHTANEN, C. M. Bile acid inhibition of Clostridium botulinum. Appl. environ Microbiol., 38:216-8, 1979.

12. LANGENEGGER, J.; DOBEREINER, J.; TOKARNIA, C. H. Botulismo epizóotico em bovinos no Brasil. Agrop. Ciba-Geygy, 20: 22-6, 1983.

13. LEITÅO, M. F. F. \& DELAZARI, I. Clostridium botulinum em solo no Estado de São Paulo. Col. Inst. Tecnol, Alim. Campinas, 13: 75-82, 1983.

14. MEYER, K. F. \& GUNNISON, J. B. Clostridium botulinum type D. N. Proc. Soc. exp. Biol. Med., 26: 88-9, 1928.

15. MOREIRA, E. C.; LIMA, J. D.: LEITÅO, R. Bolulismo no Sul de Goiás e Marajó. In: Congresso Brasileiro de Medicina Veterinária, 17, Fortaleza, 1980. Anais. Fortaleza, 1980. p. 24. [Resumo].

16. NEILL, S. D.; McLOUGHLIN, M. F.; McILROY, S. G. Type $\mathrm{C}$ botulism in cattle being fed ensiled poultry litter. Vet. Rec., 124: 558-60, 1989.

17. SAKAGUCHI, G.; SAKAGUCHI, H. K.: KAMATA, Y.; KOZAKI, S. Persistence of specific antigenic protein in the serum of chickens give intravenously botulinum toxin type B, C, D, E or F. FEMS Microbiol. Lett., 43: 355-59, 1987.

18. SEGNER, W. P. \& SCHMIDT, C. F. Nonspecific toxicities in the mouse assay test for botulinum toxin. Appl. Microbiol., 16: 1105-9, 1968.

19. SMART, J. D. \& ROBERTS, T. A. Bovine botulism. Vet. Rec., 101: 201-2, 1977.

20. SMITH, G. R. \& MURRAY, L. G. Laboratory confirmation of equine botulism. Vet. Rec., 114: 75, 1984.

21. SOUZA, A. M. Distribuição de esporos de $\mathrm{Cl}$. hotulinum no solo em torno de cadáveres decompostos de bovinos vítimas de botulismo em pastagens no Sul do Goiás. Belo Horizonte, 1985. [Dissertação de Mestrado - Escola de Veterinária da UFMG]

22. SUGYIAMA, H. Clostridium botulinum neurotoxin. Microbiol. Rev., 44: 419.48, 1980.

23. TOKARNIA, C. H.; CANELLA, C. F. C.; GUIMARÃES, J. A.; DOBEREINER, J.; LANGENEGGER, J. Deficiência de fósforo em bovinos em Piauí. Pesq. Agropec. hras., 5: 483-94, 1970.

24. TOKARNIA, C. H.; LANGENEGGER, J.; LANGENEGGER, C. H.; CARVALHO, E. B. Botulismo em bovinos no Piauí, Brasil, Pesq. agropec. bras, 5: 465-72, 1970.

25. TURNES, C. G.; LANGENEGGER, J.; SCARSI, R. M. "Mal de Alegrete", evidências de Clostridium botulinum D como agente etiológico. In: Congresso Brasileiro de Medicina Veterinária, 19º, Belém, 1984. Anais. Belém, 1984. p. 138.

Recebido para publicação em 21/2/1991 Reapresentado em 1/17/199/ Aprovado para publicação em 18/7/1991 